\title{
Helicobacter pylori Test-and-Treat Intervention Compared to Usual Care in Primary Care Patients With Suspected Peptic Ulcer Disease in the United States
}

Uri Ladabaum, M.D., M.S., A. Mark Fendrick, M.D., David Glidden, Ph.D., and James M. Scheiman, M.D. Division of Gastroenterology, Division of General Medicine, Department of Medicine, Department of Health Management and Policy, School of Public Health, Consortium for Health Outcomes, Innovation, and CostEffectiveness Studies (CHOICES), University of Michigan, Ann Arbor, Michigan; and Department of Epidemiology and Biostatistics, University of California, San Francisco, California

OBJECTIVES: The Helicobacter pylori (H. pylori) "test-andtreat" strategy in uninvestigated dyspepsia is an effective alternative to prompt endoscopy. Our aims were to determine whether the combination of an educational session and availability of office-based $H$. pylori testing (test-and-treat intervention [TTI]) increases use of the test-and-treat strategy by primary care practitioners and whether it improves patient outcomes.

METHODS: We conducted a 1-yr prospective trial of patients with suspected peptic ulcer disease in six primary care centers, three with TTI and three designated as usual care controls (UCC).

RESULTS: $H$. pylori testing was performed in $81 \%$ of 54 TTI patients and in $49 \%$ of 39 UCC patients ( $p=0.004)$. TTI and UCC patients had similar gastroenterology referral rates (24\% vs $33 \%, p=0.33$ ), endoscopy or upper GI radiography rates $(30 \%$ v $31 \%, p=0.91)$, and primary care visits per patient $(3.1 \pm 2.8 v s 3.1 \pm 2.6, p=0.92)$. TTI patients were less likely than UCC patients to receive repeated antisecretory medication prescriptions $(35 \%$ vs $66 \%, p=$ 0.003). Symptomatic status at $1 \mathrm{yr}$ and satisfaction with medical care did not differ between groups. Median (and interquartile range) annualized disease-related expenditures per patient were \$454 (\$162-932) for TTI and \$576 (\$3271435) for UCC patients ( $p=0.17)$.

CONCLUSIONS: The combination of an educational session and availability of office-based $H$. pylori testing may increase acceptance of the test-and-treat strategy by primary care providers. It remains to be determined whether increased use of the test-and-treat strategy yields significant improvements in clinical and economic outcomes compared to usual care. (Am J Gastroenterol 2002;97:3007-3014. (C) 2002 by Am. Coll. of Gastroenterology)

This work was presented in part in abstract form at Digestive Disease Week, San Diego, CA, May, 2000.

\section{INTRODUCTION}

Dyspepsia, characterized by upper abdominal pain or discomfort with or without associated symptoms, is experienced by approximately $25 \%$ of the population annually and accounts for up to $5 \%$ of primary care visits (1). Numerous practice guidelines advocate noninvasive testing for Helicobacter pylori $(H$. pylori) in patients with uncomplicated dyspepsia (2-7). Observational studies first suggested that screening for $H$. pylori might decrease endoscopic workload $(8,9)$, and cost-effectiveness analyses identified the "testand-treat" strategy as a reasonable alternative to prompt endoscopy $(10,11)$. Recently, European randomized trials have provided evidence that the test-and-treat strategy yields similar clinical outcomes and lower endoscopic rates than a strategy of prompt endoscopy $(12,13)$.

The impact of practice guidelines on patient care ultimately depends on the implementation of such guidelines by clinicians (14). Numerous strategies have been used to promote integration of clinical research findings into clinical practice, with passive dissemination of information generally proving ineffective (15). In contrast, educational outreach visits to clinicians and combinations of two or more interventions may increase the likelihood of affecting practice patterns (15).

We hypothesized that educational sessions on $H$. pylori and the test-and-treat strategy provided by gastroenterology subspecialists, in combination with establishing officebased $H$. pylori testing, would increase use of the test-andtreat strategy by primary care providers caring for patients with suspected peptic ulcer disease when compared to "usual care" after passive dissemination of information. To test this hypothesis, we designed a study comparing practice patterns and patient outcomes for patients with suspected peptic ulcer disease at three primary care centers that received the combined intervention and at three centers exposed only to passive dissemination of a practice guideline. Our primary aim was to determine whether the combined 
intervention increased use of the test-and-treat strategy. Our secondary aim was to explore whether greater acceptance of the test-and-treat strategy improved clinical outcomes and decreased disease-related expenditures compared to usual care outside the constraints of a strict protocol to reflect community practice in the United States.

\section{MATERIALS AND METHODS}

\section{Practice Guideline}

In 1996, an evidence-based practice guideline on suspected peptic ulcer disease was disseminated by campus mail to all University of Michigan Health Care System primary care providers. The guideline has been described in depth previously (16). The guideline endorsed a test-and-treat strategy in patients with symptoms suggestive of uncomplicated peptic ulcer. Prompt referral to a specialist was recommended for patients with symptoms or signs suggestive of complicated ulcer or malignancy, and for individuals with persistent or recurrent symptoms after $H$. pylori testing and initial treatment. Early referral was recommended for patients aged $\geq 50$ yr. For patients taking nonsteroidal antiinflammatory drugs, drug discontinuation was recommended, followed by the test-and-treat strategy for persistent symptoms. Proton pump inhibitor-based triple therapy was listed as the preferred $H$. pylori eradication therapy, but several regimens with costs and eradication rates were presented. For patients who tested negative for $H$. pylori, no specific therapy was recommended, and management was left to the discretion of the treating clinician.

\section{General Study Design}

The Institutional Review Board of the University of Michigan approved the study and all patients signed an informed consent document before enrollment. Within the University of Michigan Health Care System, six primary care centers in the community (all within 20 miles of the University Hospital in Ann Arbor) were included in the study. Three centers were randomized to receive no intervention, and were designated as usual care controls (UCC). Two centers were randomized and one center that was already initiating on-site $H$. pylori serological testing was assigned to receive a test-and-treat intervention (TTI), described below.

Participating providers did not practice at different sites, minimizing the potential for contamination of the UCC sites by the educational sessions provided at the TTI sites. In addition, providers were aware that this study involved patients with suspected peptic ulcer disease, but they were not aware of the specific hypotheses, the details of the study design (including the difference between UCC and TTI sites), or the outcomes of interest. The practice patterns of general medicine providers and the outcomes of patients with suspected peptic ulcer disease were compared between UCC and TTI sites, as described below.

\section{Test-and-Treat Intervention}

At the three TTI sites, 1-h educational sessions were provided to all general medicine practitioners. These interactive sessions were led by two of the authors (J.S. and U.L.). The sessions focused on the etiology and clinical presentation of peptic ulcer disease, the role of $H$. pylori in peptic ulcer disease and other causes of dyspepsia, the test-and-treat strategy, and the use of on-site $H$. pylori serological testing. In addition, the practice guideline on suspected peptic ulcer disease was reviewed. These educational sessions were combined with the establishment of office-based, whole blood H. pylori serological testing at each TTI center (FlexPack HP, Abbott Diagnostics, Abbott Park, IL). In a trial including our institution, FlexPack HP was found to have a sensitivity of $76 \%$ and a specificity of $79 \%$ (17), results similar to those of another recently published study (18). Thus, clinicians were able to test a patient for $H$. pylori during the visit in which they suspected peptic ulcer disease.

\section{Patient Population With Suspected Peptic Ulcer Disease}

From November 1996, through April 1998, general medicine practitioners in all six centers were invited to identify patients with suspected peptic ulcer disease. Although the practice guideline emphasized that symptoms are poor predictors of peptic ulceration, the following were identified as possible symptoms of peptic ulcer disease: gnawing or burning epigastric pain, pain relieved with food or antacids, and pain that occurs when the stomach is empty or that awakens the patient at night. The determination of whether a patient was suspected of having peptic ulcer disease was left to the discretion of the participating primary care providers. Thus, patients were included in the study based on the working diagnosis of the primary care provider, and not based on symptom questionnaires, tests, or other standardized instruments. This was consistent with our objective to study practice patterns and patient outcomes for patients suspected of having peptic ulcer disease by their primary care providers. Data on patients' symptoms at presentation were collected as described below.

Participating providers identified eligible patients by filling out a brief encounter form at the time of the patient visit. Patients were then contacted by the investigators by telephone and were invited to accept further information on the study by mail. For each patient who agreed to enroll in the study, the index date was defined as the day the that encounter form was filled out.

\section{Clinical Data Collection}

For $1 \mathrm{yr}$ from the index date, testing logs at the TTI centers and electronic medical records for all centers were searched prospectively to determine patients' age, sex, presenting symptoms, $H$. pylori testing and results, use of $H$. pylori eradication therapy, use of prokinetics and antisecretory medications (histamine-2 receptor antagonists and proton pump inhibitors), primary care provider visits and whether these were for persistent GI symptoms, gastroenterology 
Table 1. Answers to Questionnaire at 1 Yr After Study Entry

\begin{tabular}{|c|c|c|c|}
\hline \multicolumn{3}{|c|}{ Test-and-Treat } & $p^{*}$ \\
\hline Respondents & $48 / 54(89 \%)$ & $38 / 39(97 \%)$ & \\
\hline \multicolumn{3}{|c|}{ At present, how are your stomach symptoms compared to a year ago? } & 0.51 \\
\hline Better & $16(33 \%)$ & $9(24 \%)$ & \\
\hline Same & $9(19 \%)$ & $9(24 \%)$ & \\
\hline Worse & $1(2 \%)$ & $2(5 \%)$ & \\
\hline Daily & $5(10 \%)$ & $7(18 \%)$ & \\
\hline Over twice a wk & $10(21 \%)$ & $11(29 \%)$ & \\
\hline A few times a mo & $20(41 \%)$ & $13(34 \%)$ & \\
\hline Never & $13(27 \%)$ & $7(18 \%)$ & \\
\hline \multicolumn{3}{|c|}{ How often do you take prescription medication for your symptoms? } & 0.004 \\
\hline Daily & $15(31 \%)$ & $5(13 \%)$ & \\
\hline Daily & $0(0 \%)$ & $6(16 \%)$ & \\
\hline Over twice a wk & $8(17 \%)$ & $3(8 \%)$ & \\
\hline A few times a mo & $13(27 \%)$ & $12(32 \%)$ & \\
\hline Never & $27(56 \%)$ & $17(45 \%)$ & \\
\hline \multicolumn{3}{|c|}{ In the last year, how often did you miss work due to your symptoms? } & 0.52 \\
\hline Once a wk & $5(10 \%)$ & $3(8 \%)$ & \\
\hline Once a mo & $2(4 \%)$ & $2(5 \%)$ & \\
\hline Once in $3 \mathrm{mo}$ & $3(6 \%)$ & $4(11 \%)$ & \\
\hline Once in 6 mo & $3(6 \%)$ & $5(13 \%)$ & \\
\hline Never & $35(73 \%)$ & $24(63 \%)$ & \\
\hline \multicolumn{3}{|c|}{ How would you rate the medical care you received for these symptoms by your general doctor? } & 0.32 \\
\hline Excellent & $19(40 \%)$ & $11(29 \%)$ & \\
\hline
\end{tabular}

* For overall distribution of answers to each question.

referrals, upper GI endoscopy or radiography rates, and additional studies or referrals.

One year after enrollment, patients were contacted by phone to answer a brief questionnaire. The interviewer was not aware of which primary care center the patient had visited. Patients were asked the questions listed in Table 1.

\section{Economic Data Collection}

For patients belonging to the university-based health maintenance organization, financial databases were searched to determine medical expenditures for each patient's 1-yr study period. These databases include all paid claims for members' medical services and medications. The details of this search were the same as described in a previous study (16).

\section{Data Analysis}

Data were entered into Excel (Microsoft, Redmond, WA) and analyzed in Stata (Stata, College Station, TX) to yield summary statistics as means, proportions, or (for expenditures) medians and interquartile ranges. For both continuous and ordinal measures, results were compared between TTI and UCC centers using ordinal and log-linear regression (19) with variances corrected for clustering of subjects within centers (20). These methods account for the fact that randomization did not take place at the level of the individual patient, but that the intervention was delivered at the level of the clinical centers. Relative risks (RR) are presented with $95 \%$ CI. Statistical significance was set at $\alpha \leq$ 0.05 .

\section{RESULTS}

\section{Patient Populations}

The TTI centers identified 68 eligible patients, and 54 (79\%) agreed to participate. UCC centers identified 47 patients, and $39(85 \%)$ agreed to participate. No significant differences in age, sex, or symptoms at presentation were found between groups (Table 2).

\section{Primary Aim: Testing and Treatment for H. pylori}

Table 3 shows the proportion of patients tested for $H$. pylori, the results, and treatment for $H$. pylori in both study groups. 
Table 2. Demographic Characteristics of Study Populations and Symptoms at Presentation

\begin{tabular}{lccc}
\hline & $\begin{array}{c}\text { Test-and-Treat } \\
\text { Intervention }\end{array}$ & $\begin{array}{c}\text { Usual Care } \\
\text { Control }\end{array}$ & $\begin{array}{c}p \\
\text { Value }\end{array}$ \\
\hline Patients, n & 54 & 39 & \\
Age, yr (mean \pm SD) & $40 \pm 13$ & $43 \pm 15$ & 0.33 \\
Female, n (\%) & $33(61 \%)$ & $25(64 \%)$ & 0.77 \\
Presenting symptoms, n (\%) & & & \\
$\quad$ Abdominal pain & $51(94 \%)$ & $32(82 \%)$ & 0.09 \\
$\quad$ Nausea & $10(19 \%)$ & $6(15 \%)$ & 0.69 \\
$\quad$ Heartburn & $1(2 \%)$ & $3(8 \%)$ & 0.21 \\
Chest pain & $4(7 \%)$ & $3(8 \%)$ & 0.96 \\
\hline
\end{tabular}

In TTI centers, $81 \%$ of patients were tested for $H$. pylori, a significantly larger proportion than the $49 \%$ tested at UCC centers (all by laboratory serology) $(p=0.004)$. Patients tested at TTI centers were less likely to be $H$. pylori-positive than patients at UCC centers (43\% vs 58\%), but the difference was not statistically significant $(p=0.26)$. As shown in Table 3, $H$. pylori treatment patterns did not differ between TTI and UCC centers: nearly all $H$. pylori-positive patients and no $H$. pylori-negative patients were treated. Overall, eradication regimens did not differ significantly between TTI and UCC centers $(p=0.08)$.

\section{Secondary Aim: Clinical Outcomes Based on Medical Record Review}

MEDICATION. As shown in Figure 1, patients from TTI centers tended to receive fewer prescriptions for antisecretory medications than those from UCC centers. Patients from TTI centers were significantly less likely than patients from UCC centers to receive any proton pump inhibitor prescriptions (26 of 54 [48\%] vs 27 of 39 [69\%], $\mathrm{RR}=0.70$ [0.49-0.98], $p=0.04)$, to receive repeat histamine-2 receptor antagonist prescriptions (seven of 54 [13\%] vs 13 of 39 [33\%], $\mathrm{RR}=0.39$ [0.17-0.88], $p=0.02$ ), or to receive either repeat histamine-2 receptor antagonist or proton pump inhibitor prescriptions (19 of 54 [35\%] vs 26 of 39 [66\%], RR $=0.53[0.35-0.81], p=0.003)$. Patients from

Table 3. Testing and Treatment for Helicobacter pylori

\begin{tabular}{lccl}
\hline & $\begin{array}{c}\text { Test-and-Treat } \\
\text { Intervention }\end{array}$ & $\begin{array}{c}\text { Usual Care } \\
\text { Control }\end{array}$ & $\begin{array}{c}p \\
\text { Value }\end{array}$ \\
\hline Tested for H. pylori & $44 / 54(81 \%)$ & $19 / 39(49 \%)$ & 0.004 \\
H. pylori-positive & $19 / 44(43 \%)$ & $11 / 19(58 \%)$ & 0.26 \\
Treated for H. pylori & & & \\
H. pylori-positive & $17 / 19(90 \%)$ & $10 / 11(91 \%)$ & \\
H. pylori-negative & $0 / 25(0 \%)$ & $0 / 8(0 \%)$ & \\
Not tested for H. pylori & $0 / 10(0 \%)$ & $1 / 20(5 \%)$ & \\
H. pylori regimens in & & & \\
H. pylori-positive & & & \\
patients* & & & \\
PPI + 2 antibiotics & $9 / 17(53 \%)$ & $8 / 10(80 \%)$ & \\
PPI + 1 antibiotic & $7 / 17(41 \%)$ & $1 / 10(10 \%)$ & \\
BMT & $1 / 17(6 \%)$ & $0 / 10(0 \%)$ & \\
Unknown & $0 / 17(0 \%)$ & $1 / 10(10 \%)$ & \\
\hline
\end{tabular}

$\mathrm{BMT}=$ bismuth, metronidazole, tetracycline PPI = proton pump inhibitor. $*$ Overall distribution of regimens did not differ between groups $(p=0.08)$.

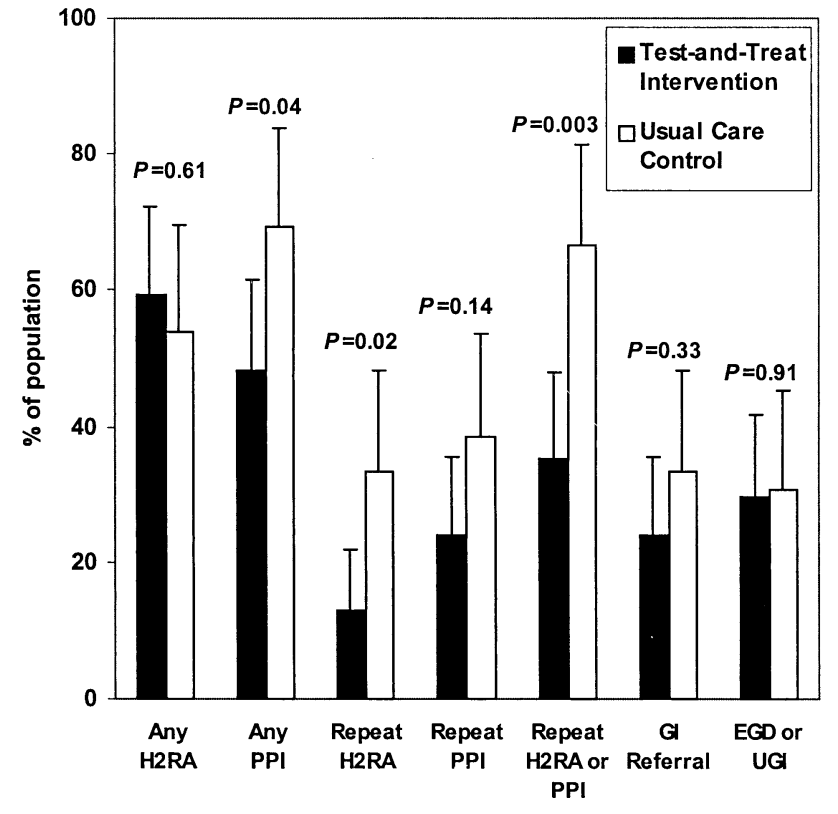

Figure 1. Antisecretory medication use and subspecialty services. Patients from test-and-treat intervention (TTI) centers were less likely to receive any prescription for a proton pump inhibitor (Any PPI), repeat histamine-2 receptor antagonist prescriptions (Repeat H2RA), or repeat antisecretory medication prescriptions (Repeat H2RA or PPI). Patients from test-and-treat intervention centers were as likely as patients from usual care control (UCC) centers to receive any prescription for a histamine-2 receptor antagonist (Any H2RA) and repeat proton pump inhibitor prescriptions (Repeat PPI), to be referred to a gastroenterologist (GI Referral), and to undergo endoscopy or upper GI contrast radiography (esophagogastroduodenoscopy [EGD] or upper GI [UGI]).

TTI centers were as likely as patients from UCC centers to receive repeat proton pump inhibitor prescriptions (13 of 54 [24\%] vs 15 of 39 [39\%], $\mathrm{RR}=0.63$ [0.34-1.16], $p=$ 0.14 ), and to receive any histamine- 2 receptor antagonist prescriptions ( 32 of 54 [59\%] vs 21 of 39 [54\%], $\mathrm{RR}=1.10$ $[0.76-1.59], p=0.61)$. Only three patients from TTI centers and two patients from UCC centers received a prescription for a prokinetic agent $(6 \%$ vs $5 \%, p=0.93)$.

PHYSICIAN VISITS. As shown in Figure 1, patients from TTI centers were as likely as patients from UCC centers to be referred to a gastroenterologist (13 of 54 [24\%] vs 13 of 39 [33\%], $\mathrm{RR}=0.72$ [0.38-1.38], $p=0.33$ ). The number of primary care visits per patient (mean $\pm \mathrm{SD}$ ) subsequent to the index visit did not differ between TTI and UCC patients $(3.1 \pm 2.8$ vs $3.1 \pm 2.6, p=0.92)$, and neither did subsequent primary care visits for GI symptoms $(0.7 \pm 1.0$ vs $0.6 \pm 0.7, p=0.78$ ).

ENDOSCOPY, RADIOGRAPHY AND OTHER INTERVENTIONS. As shown in Figure 1, patients from TTI centers were as likely as patients from UCC centers to undergo endoscopy or upper GI contrast radiography (16 of 54 [30\%] vs 12 of 39 [31\%], $\mathrm{RR}=0.96$ [0.52-1.80], $p=$ $0.91)$. In those patients who underwent endoscopic or con- 
Table 4. Findings in Patients Undergoing Endoscopy or Contrast Radiography

\begin{tabular}{lcc}
\hline & $\begin{array}{c}\text { Test-and-Treat } \\
\text { Intervention }\end{array}$ & $\begin{array}{c}\text { Usual Care } \\
\text { Control }\end{array}$ \\
\hline Number (\% of total) finding* & $16 / 54(30 \%)$ & $12 / 39(31 \%)$ \\
Normal & $9 / 16(56 \%)$ & $6 / 12(50 \%)$ \\
Esophagitis & $3 / 16(19 \%)$ & $1 / 12(8 \%)$ \\
Gastric ulcer & $1 / 16(6 \%)$ & 0 \\
Duodenal ulcer & 0 & $2 / 12(17 \%)$ \\
Gastric or duodenal erosions & $3 / 16(19 \%)$ & $3 / 12(25 \%)$ \\
* Overall distribution of findings did not differ between groups $(p=0.51)$.
\end{tabular}

* Overall distribution of findings did not differ between groups $(p=0.51)$.

trast radiographic investigation, endoscopy was used most often (15 of 16 in TTI and eight of 12 in UCC patients), and there was no difference in the distribution of findings between groups $(p=0.51)$ (Table 4$)$.

Abdominal ultrasound was obtained in 10 TTI and five UCC patients $(p=0.47)$ and cholecystectomy was performed in three patients from each group $(p=0.68)$.

\section{Secondary Aim: Clinical Outcomes Based on Patient Questionnaire at $1 \mathrm{Yr}$}

The questionnaire was answered at 1 yr by 48 of 54 (89\%) of TTI patients, and 38 of 39 (97\%) of UCC patients (Table 1). Improvement in symptoms ("better" or "much better") was reported by $79 \%$ of patients in TTI centers and $71 \%$ of patients in UCC centers ( $\mathrm{RR}=1.11$ [0.87-1.43], $p=0.40)$, whereas frequent ("daily" or "over twice a week") symptoms were reported by $31 \%$ and $47 \%$ of patients from these centers, respectively, $(\mathrm{RR}=0.66$ [0.39-1.43], $p=0.13$ ). Frequent use of prescription medications was reported by $31 \%$ of patients in TTI centers and $32 \%$ of patients in UCC centers $(\mathrm{RR}=0.99[0.53-1.86], p=0.97)$, whereas frequent use of over-the-counter medications was reported by $17 \%$ and $24 \%$ of patients, respectively, $(\mathrm{RR}=0.70[0.30$ 1.65 ], $p=0.42$ ). Missed work because of symptoms was reported by $27 \%$ of patients in TTI centers and $37 \%$ of patients in UCC centers ( $\mathrm{RR}=0.74$ [0.39-1.37], $p=0.33$ ). Quality of care was rated as "very good" or "excellent" by $58 \%$ of patients in TTI centers and $66 \%$ of patients in UCC centers $(\mathrm{RR}=0.89[0.64-1.23], p=0.48)$.

\section{Secondary Aim: Economic Outcomes}

Economic data were available for the patients who were members of the university-based health maintenance organization: 38 of $54(70 \%)$ TTI patients, and 16 of 39 (41\%) UCC patients. This subpopulation tended to be younger than the entire study population (age $37 \pm 10 \mathrm{yr} v s 46 \pm 17 \mathrm{yr}$, $p=0.004)$. However, within this subpopulation, the age, sex distribution, symptoms, primary care visits, gastroenterology referral rate, and endoscopy or radiography rates were similar between TTI and UCC centers (as in the entire study population), and rates of $H$. pylori testing reflected the results in the entire study population (data not shown).

Median (interquartile range) total disease-related expenditures per patient were $\$ 454$ (\$162-932) for TTI patients and $\$ 576(\$ 327-1435)$ for UCC patients $(p=0.17)$. The mean $( \pm \mathrm{SD})$ endoscopy-related expenditure for those who underwent endoscopy was $\$ 703 \pm \$ 328$ for TTI patients and $\$ 649 \pm \$ 410$ for UCC patients.

\section{DISCUSSION}

In this prospective study, the combination of an educational session led by gastroenterology subspecialists and the availability of office-based serological testing for $H$. pylori was associated with an increase in the use of the H. pylori test-and-treat strategy in primary care patients with suspected peptic ulcer disease when compared to passive dissemination of a practice guideline. Increased use of the test-and-treat strategy was not associated with significantly lower gastroenterology referral rates, endoscopy or upper GI radiography rates, primary care visit rates, and diseaserelated expenditures, or with significant improvements in patients' self-assessed clinical status, satisfaction with care, and medication use at $1 \mathrm{yr}$.

We did not randomize patients to specific management strategies; rather, we investigated the impact of an intervention designed to increase use of the test-and-treat strategy for suspected peptic ulcer disease. Our primary question was: what is the effect of such an intervention on the practice of primary care providers? Our secondary question was: what are the clinical and economic outcomes of patients with suspected peptic ulcer disease when they are managed with the test-and-treat strategy compared to "usual care"? In particular, we wished to examine the test-and-treat strategy outside the context of a strict research protocol to reflect clinical practice in the community in the US.

Our primary finding that practitioners were indeed more likely to pursue testing for $H$. pylori in centers that received the combined intervention compared to centers that did not is consistent with previous research on interventions designed to affect practice patterns (15). Educational outreach visits and combinations of two or more interventions have been shown to affect the practice of clinicians, whereas passive dissemination of information generally proves ineffective (15). Given our study design, we cannot determine how much of the combined intervention's impact can be attributed to the on-site test or to the outreach session, and we cannot determine the impact of passive guideline dissemination alone compared to no intervention at all.

Regarding our secondary aim, intermediate-term clinical and economic outcomes for TTI center patients were not significantly different from those of UCC center patients, although trends were noted toward improved symptomatic status at $1 \mathrm{yr}$ and decreased resource use and cost in TTI compared to UCC patients. In interpreting these findings, several limitations of our study must be noted.

First, a relatively large number of patients in the UCC centers and not all patients in TTI centers underwent $H$. pylori testing and treatment. Therefore, any difference in outcomes between the "ideal" test-and-treat strategy and a "usual care" control strategy could have been diluted. Sec- 
ond, this is a small study with limited power to detect differences in patient outcomes. For instance, the power to detect a difference between gastroenterology referral rates of $24 \%$ in TTI centers and $33 \%$ in UCC centers at $\alpha \leq 0.05$ is only 0.16 with our sample size; a much larger study would be needed to identify such a difference as statistically significant (393 subjects/group for power of 0.8 and $\alpha \leq 0.05$ ).

Third, no formal testing at entry or at follow-up (e.g., endoscopy, confirmation of $H$. pylori eradication) was performed, and therefore parameters such as the actual peptic ulcer prevalence and the success rate of $H$. pylori eradication are unknown in our study population. Eradication rates of $70-87 \%$ have been reported in community practice in the US (21), but it is unclear whether these results can be extrapolated to our study. Some of the patients in our study who continued to use antisecretory medication may have had persistent peptic ulcer disease because of unsuccessful H. pylori treatment, but it is important to note that approximately one half of patients with peptic ulcer disease report regular use of prescription medication to treat upper GI symptoms $1 \mathrm{yr}$ after successful eradication of $H$. pylori infection (22).

Fourth, the relatively poor specificity of the serology test that we studied $(17,18)$ could have influenced the results, particularly if the population tested actually had a low prevalence of $H$. pylori infection. More specific testing with urea breath testing or stool antigen to detect active $H$. pylori infection, which should be distinguished from false positive serology as well as true positive serology in the absence of active infection, may have reduced significantly any inappropriate use of antimicrobial therapy (23).

Finally, patients were included in this study on the basis of the treating clinician's suspicion of peptic ulcer disease and not a more complex, standardized set of inclusion criteria, and patient interviews at $1 \mathrm{yr}$ did not use validated instruments. Nonetheless, a valuable aspect of our study is that it reflects clinical practice and not a strict protocol that might be difficult to apply in the clinical setting, and the patient questionnaires provide valuable information on clinical status and satisfaction at $1 \mathrm{yr}$.

Thus, our results suggest that we may be able to increase acceptance of a test-and-treat strategy in primary care with education and near-patient testing, but should we aim to do this? Numerous practice guidelines have recommended a test-and-treat strategy in uninvestigated dyspepsia (3-7). Recent European randomized trials have reported similar clinical outcomes, reduced endoscopy rates, and lower expenditures for the test-and-treat strategy compared to prompt endoscopy $(12,13,24-26)$. Preliminary results from another study suggest that symptom improvement and overall costs are comparable with the test-and-treat strategy, a "test-and-endoscope" strategy, empiric proton pump inhibitor therapy, and prompt endoscopy (27). Therefore, current evidence suggests that the various strategies achieve comparable intermediate-term clinical outcomes, and that the test-and-treat strategy reduces endoscopy rates and may decrease expenditures compared to prompt endoscopy.

At present, few data are available to support the effectiveness of initial endoscopy in the evaluation of dyspepsia (28). Given that intermediate term clinical outcomes seem to be comparable with the various possible management strategies $(12,13,24-26,29)$ and that test-and-treat may be less costly than prompt endoscopy, a noninvasive initial approach may remain the first choice in primary care settings, based on cost considerations. However, this approach ignores factors such as patient satisfaction and reassurance. Studies suggest that patient satisfaction may be greatest with prompt endoscopy $(12,27)$. A normal endoscopy may provide valuable reassurance to patients, and there is evidence that a normal endoscopy improves patients' quality of life in the short term (30). Notably, although most patients with suspected peptic ulcer may be interested in establishing a firm diagnosis, they are willing to pay relatively little for such information (median of less than \$50) (31). Finally, it remains to be determined how many patients who are managed noninvasively avoid endoscopy altogether in the long term.

Although it is not clear whether the test-and-treat approach has advantages over other noninvasive strategies in the shorter term (32), it is unknown whether the TTI in our study could yield longer term benefits over UCC that may not be apparent at $1 \mathrm{yr}$. In addition to cure in patients with active $H$. pylori-related peptic ulcer disease, H. pylori eradication has the potential to prevent future peptic ulcer (3336) and the potential (albeit unproven) to reduce the incidence of gastric malignancy (37-39), and it may cure symptoms in one of 15 patients with functional dyspepsia (40).

In conclusion, the combination of an educational session led by gastroenterology subspecialists and the availability of office-based $H$. pylori testing may increase acceptance of the $H$. pylori test-and-treat strategy by primary care providers. Further studies are necessary to determine whether increased acceptance of the test-and-treat strategy achieves significant improvements in intermediate term patient outcomes or disease-related expenditures compared to "usual care." It remains to be established whether, by eliminating a risk factor for several chronic diseases, the test-and-treat strategy yields benefits in the long term that are not evident in the intermediate term.

\section{ACKNOWLEDGMENTS}

This work was supported by an American Digestive Health Foundation/TAP Pharmaceuticals Outcomes Research Pilot Program Award; by an unrestricted research grant from Astra Merck to the University of Michigan Gastroenterology Division; and by National Institutes of Health grant M01-RR00079. The authors express their profound appreciation to Marsha Brosnan for her assistance with collection of data on serological testing, and to Rebecca Ramsey and 
Jill Halman, Ph.D., for their assistance with collection of the economic data. The authors thank the following individuals who helped to identify eligible patients for the study: Cheryl Bord, R.N., John Brinley, M.D., Timothy Cook, M.D., Karen Cummings, R.N., Gerald Dreslinski, M.D., Dan Dubay, M.D., Janice Farrehi, M.D., Cathy Gardner, R.N., Steven Gradwohl, M.D., Mary Johnson, M.D., Anita Kirsch, M.D., Kate Maddox, R.N., Larry McMaster, M.D., Sonya Mitrovich-Lozowski, M.D., Jennifer Nastelin, M.D., Thomas O'Connor, M.D., Rajesh Patel, M.D., Chris Persson, M.D., Candice Roskoph, M.D., Pat Rutowski, R.N., Amy Sanders, M.D., Mark Skalski, M.D., Barbara Soyster, M.D., David Spahlinger, M.D., Connie Standiford, M.D., Jeffrey Sweet, M.D., Kim Turgeon, M.D., David Vallance, M.D., Denege Ward, M.D., Breton Weintraub, M.D., Steven Yarows, M.D., and Chen Yun-Chang, M.D.

Reprint requests and correspondence: Uri Ladabaum, M.D., M.S., Division of Gastroenterology, S-357, Box 0538, University of California, San Francisco, 513 Parnassus Avenue, San Francisco, CA 94143-0538.

Received Dec. 26, 2001; accepted June 20, 2002.

\section{REFERENCES}

1. Talley NJ, Silverstein MD, Agreus L, et al. AGA technical review: Evaluation of dyspepsia. Gastroenterology 1998;114: 582-95.

2. Axon AT, Bell GD, Jones RH, et al. Guidelines on appropriate indications for upper gastrointestinal endoscopy. Working Party of the Joint Committee of the Royal College of Physicians of London, Royal College of Surgeons of England, Royal College of Anaesthetists, Association of Surgeons, the British Society of Gastroenterology, and the Thoracic Society of Great Britain. Br Med J 1995;310:853-6.

3. Current European concepts in the management of Helicobacter pylori infection. The Maastricht Consensus Report. European Helicobacter Pylori Study Group. Gut 1997;41:8-13.

4. American Gastroenterological Association medical position statement: Evaluation of dyspepsia. Gastroenterology 1998; 114:579-81.

5. Lam SK, Talley NJ. Report of the 1997 Asia Pacific Consensus Conference on the management of Helicobacter pylori infection. J Gastroenterol Hepatol 1998;13:1-12.

6. Veldhuyzen van Zanten SJ, Flook N, Chiba N, et al. An evidence-based approach to the management of uninvestigated dyspepsia in the era of Helicobacter pylori. Canadian Dyspepsia Working Group. Can Med Assoc J 2000;162(suppl 12): S3-23.

7. Peterson WL, Fendrick AM, Cave DR, et al. Helicobacter pylori-related disease: Guidelines for testing and treatment. Arch Intern Med 2000;160:1285-91.

8. Sobala GM, Crabtree JE, Pentith JA, et al. Screening dyspepsia by serology to Helicobacter pylori. Lancet 1991;338:94-6.

9. Patel P, Khulusi S, Mendall MA, et al. Prospective screening of dyspeptic patients by Helicobacter pylori serology. Lancet 1995;346:1315-8.

10. Fendrick AM, Chernew ME, Hirth RA, et al. Alternative management strategies for patients with suspected peptic ulcer disease. Ann Intern Med 1995;123:260-8.

11. Silverstein MD, Petterson T, Talley NJ. Initial endoscopy or empirical therapy with or without testing for Helicobacter pylori for dyspepsia: A decision analysis. Gastroenterology 1996;110:72-83.

12. Lassen AT, Pedersen FM, Bytzer P, et al. Helicobacter pylori test-and-eradicate versus prompt endoscopy for management of dyspeptic patients: A randomised trial. Lancet 2000;356: 455-60.

13. Jones R, Tait C, Sladen G, et al. A trial of a test-and-treat strategy for Helicobacter pylori positive dyspeptic patients in general practice. Int J Clin Pract 1999;53:413-6.

14. Weingarten $S$. Translating practice guidelines into patient care: Guidelines at the bedside. Chest 2000;118:4-7S.

15. Bero LA, Grilli R, Grimshaw JM, et al. Closing the gap between research and practice: An overview of systematic reviews of interventions to promote the implementation of research findings. The Cochrane Effective Practice and Organization of Care Review Group. Br Med J 1998;317:465-8.

16. Ladabaum U, Fendrick AM, Scheiman JM. Outcomes of initial noninvasive Helicobacter pylori testing in U.S. primary care patients with uninvestigated dyspepsia. Am J Gastroenterol 2001;96:2051-7.

17. Chey WD, Murthy U, Shaw S, et al. A comparison of three fingerstick, whole blood antibody tests for Helicobacter pylori infection: A United States, multicenter trial. Am J Gastroenterol 1999;94:1512-6.

18. Ladas SD, Malamou H, Giota G, et al. Prospective evaluation of a whole-blood antibody test (FlexPack HP) for in-office diagnosis of Helicobacter pylori infection in untreated patients. Eur J Gastroenterol Hepatol 2000;12:727-31.

19. Agresti A. An introduction to categorical data analysis. New York: Wiley, 1996.

20. Liang KY, Zeger SL. Longitudinal data analysis using generalized linear models. Biometrika 1986;73:13-22.

21. Fennerty MB, Lieberman DA, Vakil N, et al. Effectiveness of Helicobacter pylori therapies in a clinical practice setting. Arch Intern Med 1999;159:1562-6.

22. Fendrick AM, Chey WD, Margaret N, et al. Symptom status and the desire for Helicobacter pylori confirmatory testing after eradication therapy in patients with peptic ulcer disease. Am J Med 1999;107:133-6.

23. Chey WD, Fendrick AM. Noninvasive Helicobacter pylori testing for the "test-and-treat" strategy: A decision analysis to assess the effect of past infection on test choice. Arch Intern Med 2001;161:2129-32.

24. Asante MA, Mendall M, Patel P, et al. A randomized trial of endoscopy vs no endoscopy in the management of seronegative Helicobacter pylori dyspepsia. Eur J Gastroenterol Hepatol 1998;10:983-9.

25. Heaney A, Collins JS, Tham TC, et al. A prospective study of the management of the young Helicobacter pylori negative dyspeptic patient - can gastroscopies be saved in clinical practice? Eur J Gastroenterol Hepatol 1998;10:953-6.

26. Heaney A, Collins JS, Watson RG, et al. A prospective randomised trial of a "test and treat" policy versus endoscopy based management in young Helicobacter pylori positive patients with ulcer-like dyspepsia, referred to a hospital clinic. Gut 1999;45:186-90.

27. Duggan A, Elliot C, Tolley K, et al. Randomized controlled trial of four dyspepsia management strategies in primary care with 12 months follow-up. Gastroenterology 2000;118:A438 (abstract).

28. Ofman JJ, Rabeneck L. The effectiveness of endoscopy in the management of dyspepsia: A qualitative systematic review. Am J Med 1999; 106:335-46.

29. Laheij RJ, Severens JL, Van de Lisdonk EH, et al. Randomized controlled trial of omeprazole or endoscopy in patients with persistent dyspepsia: A cost-effectiveness analysis. Aliment Pharmacol Ther 1998;12:1249-56. 
30. Wiklund I, Glise H, Jerndal P, et al. Does endoscopy have a positive impact on quality of life in dyspepsia? Gastrointest Endosc 1998;47:449-54.

31. Hirth RA, Bloom BS, Chernew ME, et al. Willingness to pay for diagnostic certainty: Comparing patients, physicians, and managed care executives. J Gen Intern Med 1999;14:193-5.

32. Hession PT, Malagelada J. The initial management of uninvestigated dyspepsia in younger patients-the value of symptom-guided strategies should be reconsidered. Aliment Pharmacol Ther 2000;14:379-88 (review article).

33. Nomura A, Stemmermann GN, Chyou PH, et al. Helicobacter pylori infection and the risk for duodenal and gastric ulceration. Ann Intern Med 1994;120:977-81.

34. Hsu PI, Lai KH, Tseng HH, et al. Eradication of Helicobacter pylori prevents ulcer development in patients with ulcer-like functional dyspepsia. Aliment Pharmacol Ther 2001;15:195-201.

35. Scheiman JM, Bandekar RR, Chernew ME, et al. Helicobacter pylori screening for individuals requiring chronic NSAID therapy: A decision analysis. Aliment Pharmacol Ther 2001; 15:63-71.
36. Chan FK, Chung SC, Suen BY, et al. Preventing recurrent upper gastrointestinal bleeding in patients with Helicobacter pylori infection who are taking low-dose aspirin or naproxen. N Engl J Med 2001;344:967-73.

37. Parsonnet J, Harris RA, Hack HM, et al. Modelling costeffectiveness of Helicobacter pylori screening to prevent gastric cancer: A mandate for clinical trials. Lancet 1996;348: 150-4.

38. Fendrick AM, Chernew ME, Hirth RA, et al. Clinical and economic effects of population-based Helicobacter pylori screening to prevent gastric cancer. Arch Intern Med 1999; 159:142-8.

39. Uemura N, Okamoto S, Yamamoto S, et al. Helicobacter pylori infection and the development of gastric cancer. N Engl J Med 2001;345:784-9.

40. Moayyedi P, Soo S, Deeks J, et al. Systematic review and economic evaluation of Helicobacter pylori eradication treatment for non-ulcer dyspepsia. Dyspepsia Review Group. Br Med J 2000;321:659-64. 